\title{
PARALISIA FACIAL BILATERAL
}

\author{
J. Fortes-Rego *
}

A paralisia bilateral do nervo facial é um achado infrequente, o que contrasta com a variedade unilateral que, segundo Cawthorne ${ }^{5}$, ocorre, mensalmente, na Inglaterra, em 12 de cada 100.000 doentes. Enquanto a grande maioria desta encaixa-se na categoria idiopática ${ }^{14}$, a forma bilateral aparece como sendo um elemento apenas no contexto sintomático de várias entidades clínicas. Hora e Elwell, citados por Rontal e Sigel ${ }^{36}$, estabelecem, modificando classificação original de Ganz, oito situações em que a paralisia facial bilateral pode evidenciar-se: 1 - congênita (síndrome de Moebius e talidomida); 2 - infecção: a) central (malária, meningite, encefalite, poliomielite, mononucleose infecciosa, sífilis e tétano); b) periférica, podendo ser virósica (herpes zoster) ou bacteriana (otite média aguda ou crônica, lepra, difteria); 3 - neoplasma (glioma pontino e leucemia); 4 - traumatismo; 5 - metabólica (diabete melito e neuropatia alcoólica); 6 - lesōes centrais não inflamatórias (causas vasculares, esclerose múltipla e paralisia bulbar progressiva); 7 - doenças de origem não neurogênica (ausência congênita da musculatura facial, miastenia grave e doença psiquiátrica); 8 - associação com doenças de etiologia indeterminada (sindrome de Guillain-Barré-Strohl, de Heerfordt, de Melkersson e periarterite nodosa).

A classificação supra é bastante objetiva e servirá de roteiro para esta explanação; alguns tópicos nela incluídos nos parecem de menor interesse prático, seja porque a diplegia facial praticamente não exista neles de forma isolada, seja por constituir-se numa eventualidade excepcional. Assim, a sínđrome de Moebius, por exemplo, justifica nossa primeira ressalva, desde que, por definição, abrange os núcleos de origem do VI par, também bilateralmente. Já o herpes zoster, cuja importância na gênese da paralisia facial periférica é destacada por quantos têm-se dedicado ao tema ${ }^{14}$, limita-se, pelo menos nos trabalhos por nós consultados, invariavelmente, a um só lado. Com relação ao diabete melito, a literatura é pródiga em associá-lo à paralisia facial, variando tal incidência de 6 a $66 \%$ nos casos de paralisia unilateral $^{3}$; referências da mesma associação, porém com o comprometimento bilateral do nervo, apenas encontramos em Naufal e Schuknecht ${ }^{34}$. Quanto aos gliomas pontinos, embora seja de norma o envolvimento do VII par, quase sempre bilateral, seria ilógico esperar-se - pelas próprias características da lesão - que isto ocorresse isoladamente, isto é, respeitando outros nervos e as longas vias, mormente se considerarmos as exíguas dimensões das estrutu-

Departamento de Medicina Especializada da Faculdade de Ciências da Saúde da Universidade de Brasilia: * Professor-Assistente. 
ras que compõem o tronco cerebral; de fato, em 13 casos de tumores desta localização, constatamos comprometimento do facial em $92,3 \%$, porém em nenhuma só vez de forma isolada ${ }^{16}$. Finalmente, um último reparo relaciona-se à sindrome de Melkersson, onde a paralisia bilateral é alternante e não simultânea ${ }^{17}$.

Por outro lado, outros itens da mesma classificação estão a merecer maior atenção.

A mononucleose infecciosa afeta o sistema nervoso central em menos de $1 \%$ dos casos, porém com inusitada seletividade para o nervo facial, o que justifica o frequente relato de casos de diplegia facial pura $2,4,7,9,31,37$. A sindrome de Guillain-Barré-Strohl apresenta-se como uma polineurite infecciosa acometendo primariamente os nervos periféricos, embora existam formas medular, bulbar e cerebral. Em termos de comprometimento de nervos cranianos, a doença tem grande afinidade pelo facial, na maioria das vezes bilateral, eventualmente constituindo-se no único sinal neurológico 20,29 , 36, 38. Não obstante a afirmação de Haymaker e Kernoham, citados por Mc Govern ${ }^{29}$, de que os IX e $\mathrm{X}$ pares são os mais frequentemente lesados, o predomínio do facial é reconhecido pela maioria absoluta dos autores ${ }^{12,26}$, $27,35,36$. Paralisia facial bilateral consecutiva a traumatismo é uma condição rara, como se depreende de nossa recente revisão sobre a matéria ${ }^{15}$.

Paralisia de nervo craniano associada com sarcoidose é conhecida como sindrome de Heerfordt e Lambert e Richards, citados por Mc Govern ${ }^{29}$, encontraram-na em 24 de 179 casos de sarcoidose: três dos 24 pacientes tinham paralisia facial unilateral e igual número exibia uma diplegia facial. Entre os 340 casos de paralisia facial de Groves ${ }^{19}$, a sarcoidose é incriminada 14 vezes, sem que outros detalhes sejam oferecidos. Também de forma um tanto vaga, outros autores registram a possibilidade de acometimento uni ou bilateral do VII par na sarcoidose 21,36 . A literatura revisada registra ainda, como causas de paralisia facial bilateral: periarterite nodosa ${ }^{10}$, leptospirose $^{39}$, linfoma de Burkitt ${ }^{30}$. Dos 11 casos de Kobayashi ${ }^{23}, 2$ são traumáticos, 2 de origem pós-operatória, 2 congênitos, 2 de natureza sintomática e 3 idiopáticos.

A seguir faremos o relato de um caso de paralisia facial bilateral surgida após quadro infeccioso bacteriano e, provavelmente, também virótico.

\section{OBSERVACX̃O}

B. P. S. (Reg. 124732), com 23 anos de idade, sexo masculino, moreno, solteiro, admitido no Hospital Universitário de Brasillia em 11-10-1974 para tratamento de meningite meningocócica. Ao nono dia de internação estava assintomático, exceto por sentir dor na boca e dificuldade para falar em face de lesões surgidas no lábio inferior e interpretadas como de natureza herpética. Em 23-10-1974 recebeu alta, com tais lesões aparentemente em regressão. Dez dias após apresentou "gripe" com febre moderada e notou que sua comissura labial desviara-se para a esquerda, referindo, ademais, sensações parestésicas nos dois lados da face e nos quatro membros; contudo, somente em 5-12-1974 procurou novamente o Hospital, por con- 
seguinte depois de aproximadamente um mês da instalação do quadro. O exame neurológico, então realizado, detectou acentuada paresia facial periférica bilateral. Exibia um facies quase parado, com apagamento do sulco nasogeniano direito e discreto desvio da comissura labial para a esquerda. Sinal dos cilios bilateral, podendo-se vencer com extrema facilidade a contração de ambos os orbiculares; a contração dos frontais era igualmente deficiente, mais ainda à tireita. O erflexo superciliar oferecia resposta débil dos dois lados. O exame dos demais nervos cranianos não revelou anormalidades, o mesmo ocorrendo com o resto do exame neurológico, devendo-se ressaltar que os reflexos profundos estavam presentes simetricamente nos quatro membros e que a sensibilidade estava preservada em todas as suas modalidades. Exames complementares - LCR normal; hemograma, eosinofilia; velocidade de eritrossedimentacão, 18 na primeira hora; dosagens de uréia, cleatinina e glicose, exame sumário de urina e estudo radiológico do crânio normais; sorologia negativa para lues. A alta ocorreu em 19-12-1974 e a reglessão do deficit motor vinha-se processando lentamente. Desde então, o paciente não mais retornou ao hospital.

\section{COMENTARIOS}

Considerando que a normalidade do líquido cefalorraquidiano descarta a possibilidade de uma síndrome de Guillain-Barré-Strohl, pensamos que o presente caso deve ser catalogado numa das eventuadidades, que abaixo discutiremos.

1) Paralisia de Bell bilateral - A paralisia de Bell é definida como sendo uma paralisia facial periférica, para a qual não se encontra uma causa; paralisia de Bell bilateral é diagnosticada quando a paralisia afeta ambos os lados da face simultaneamente. Trata-se de uma condição incomum, ocorrendo em cerca de 1,5 a $2 \%$ de todos os pacientes com paralisia de Bell ${ }^{36}$. Merwarth, citado por Mc Govern ${ }^{29}$, em uma série de 500 casos de paralisia facial, relata 8 bilaterais, 3 dos quais classificados como paralisia de Bell. A quase totalidade das grandes casuísticas sobre paralisia facial idiopática nem mesmo a mencionam, a exemplo de Adour e Wingerd ${ }^{1}$, Cawthorne ${ }^{5}$, Cawthorne e Wilson ${ }^{6}$, com 856, 532 e 473 casos, respectivamente. Para aceitarmos este diagnóstico com relação ao nosso paciente, teríamos que partir da premissa de que o surgimento da doença durante a convalescença de dois processos infecciosos não passou de mera coincidência, desprezando assim dois fatores virtualmente causadores de paralisia facial bilateral.

2) Complicação da meningite meningogócica - Rontal e Sigel ${ }^{36}$ referem-se à meningite como causa de paralisia facial bilateral, porém não tecem considerações a respeito. Miller ${ }^{32}$, estudando o trajeto do facial pelo ângulo pontocerebelar, destaca que, no mencionado sítio, a paralisia é frequentemente bilateral, podendo ocorrer em várias meningites crônicas. Garcia Fernandez ${ }^{18}$, descrevendo o quadro clínico da meningoencefalite luética - sabidamente de natureza crônica - diz que as paralisias dos nervos cranianos afetam a um ou vários (tendo já sido assinaladas em todos) e podem ser uni ou bilaterais. Farias da Silva e col. ${ }^{11}$, em 5 casos de meningite criptocócica, encontraram paresia facial central unilateral em dois, 
ao lado de sinais próprios do acometimento de outros pares cranianos. Hermans e col. ${ }^{21}$, revendo a literatura sobre meningite de Mollaret, encontraram 20 casos até 1972. Esta entidade caracteriza-se por curtos episódios recorrentes de meningite asséptica e pela presença de células endoteliais no líquido cefalorraquidiano; os ataques ocorrem subitamente e os sintomas alcançam sua intensidade máxima dentro de poucas horas; os sinais neurológicos são raros e, em apenas um caso, está registrada uma paresia do nervo facial, sem outras informações. Não nos foi possível encontrar uma referência sequer a diplegia facial associada a meningite bacteriana aguda, o que aliás concorda com nossa própria experiência, já que no surto de meningite meningocócica que grassou no Distrito Federal no ano de 1974, durante o qual pelo menos duas centenas de pacientes foram internados no Hospital Universitário de Brasília para tratamento, em nenhum deles pudemos constatar comprometimento do nervo facial na fase aguda da doença, enquanto no periodo de convalescença, apenas temos conhecimento do caso que ora focalizamos.

3) Complicação do herpes simples - Desde que a paralisia facial tem-se assoriado a várias viroses, tais como caxumba, varicela, poliomielite, influenza e herpes zoster, a hipótese de uma origem virótica tem sido considerada 25, 38, 42. Schuring e Saunders, citados por Mc Govern ${ }^{29}$, dissertando sobre a possível relação entre infecção a vírus e diplegia facial, consideram válida a idéia, pelo menos em alguns casos, a exemplo de um próprio, no qual a diplegia fora precedida por uma doença aguda, presumivelmente virótica.

Com relação ao vírus do herpes simples, suas manifestações clínicas foram bem estudadas por Kilbourne e Horstall, citados por Fernández-Martin ${ }^{13}$, que destacam a escassa frequência da participação do sistema nervoso. Provavelmente, porém, esta assertiva é mais aparente do que real, considerando-se a demonstração de Slavin e Ferguson, citados por Morris ${ }^{33}$, de que erupções zosterianas recorrentes da pele são devidas ao vírus do herpes simples; a partir de então vários autores têm enfatizado que lesões de pele produzidas pelos vírus varicela-zoster e herpes simples podem parecer idênticas, devendo a diferenciação basear-se na história de erupções recorrentes ou em culturas do virus ${ }^{33}$. O herpes simples simulando herpes zoster seria designado "zoster-like" ${ }^{8}$. Tomita e col. ${ }^{40}$, estudando 22 casos de síndrome de Ramsay-Hunt, encontraram em 18, elevação do título de anticorpos para o vírus do herpes zoster, enquanto 3 o tinham apenas com relação ao vírus do herpes simples.

Atualmente, à parte da associação relativamente frequente do vírus do herpes simples com meningites e encefalites assépticas não bacterianas ${ }^{13}, 41$, têm sido descritos vários casos de neuralgias, sobretudo do ciático 8 22, 24, 33 . Especificamente em relação ao VII par, Mc Cormick ${ }^{28}$ postulou a hipótese de representar este vírus uma importante causa de paralisia de Bell. Segundo ele, o vírus residiria nos axônios e terminaçōes nervosas, onde estaria protegido dos efeitos neutralizantes de anticorpos ou linfócitos sensibilizados. 
Como consequência de traumatismos ou insultos metabólicos, o vírus libertar-se-ia do nervo, infectando suas células epiteliais ou células de Schwann e progrediria centripetamente por transmissão célula-a-célula. Assim, quando a inflamação do endoneuro atingisse o aqueduto de Falópio, o edema e a pressão sobre o nervo poderiam resultar em paralisia. Fernández Martin ${ }^{13}$ publicou um caso de diplegia facial pura no curso de uma infecção por herpes simples, afirmando tratar-se de comunicação ímpar na literatura mundial e conclui que a paralisia facial periférica bilateral deve ser incluída no grupo das neurites para ou pós-infecciosas que, provavelmente, reconhecem uma gênese imunitária.

Como conclusão, acreditamos que nosso paciente desenvolveu uma diplegia facial em consequência da infecção herpética.

\section{RESUMO}

E aprsentado um caso de diplegia facial surgida após meningite meningocócica e infecção por herpes simples. Depois de discutir as diversas condições que o fenômeno pode apresentar-se, o autor inclina-se por uma etiologia herpética.

\section{SUMMARY}

Bilateral facial paralysis: a case report

A case of bilateral facial paralysis following meningococcal meningitis and herpes simplex infection is reported. The author discusses the differential diagnosis of bilateral facial nerve paralysis which includes several diseases and syndromes and concludes by herpetic aetiology.

\section{REFERENCIAS}

1. ADOUR, K. K. \& WINGERD, J. - Idiopathic facial paralysis (Bell's palsy): factors affecting severity and outcome in 446 patients. Neurology (Minneapolis) 24:1112, 1974 .

2. ALEXANDER, J. C.; ESPIR, M. C. \& PUGH, V. W. - Facial diplegia in infectious mononucleosis. Brit. Med. J. 1:1570, 1964.

3. AMINOFF, M. J. \& MILLER, A. C. - The prevalence of diabetes mellitus

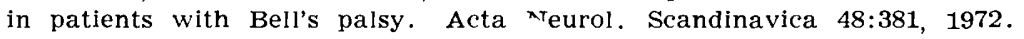

4. BOWIE, J. C. - Infectious mononucleosis. Brit. Med. J. 1:1316, 1964.

5. CAWTHORNE, T. - Intratemporal facial palsy. Arch. Otolaryng. 90:789, 1969 .

6. CAWTHORNE, T. \& WILSON, T. - Indications for intratemporal facial nerve surgery. Arch. Otolaryng. 78:429, 1963.

7. CHAlmers, R. B. - Facial diplegia in infectious mononucleosis. Brit. Med. J. $1: 1316,1964$.

8. Constantine, V. S.; Francis, R. D. \& MONTES, L. F. - Association of recurrent herpes simplex with neuralgia. .TAMA 205:181, 1968. 
9. DAVIDSON, R. J. L. \& SALTER, H. H. - Infectious mononucleosis presenting with facial diplegia. Brit. Med. J. 1:954, 1964.

10. DUDLEY, J. P. \& GOODMAN, M. - Periarteritis nodosa and bilateral facial paralysis. Arch. Otolaryng. 90:139, 1969.

11. FARIAS DA SIlva, W.; TRAVASSOS, F.; CODECEIRA Jr., A. \& FORTES-REGO, J. - Criptococose do sistema nervoso central. Neurobiologia (Recife) $31: 174,1968$.

12. FARIAS DA Silva, W.; VAlenÇA, M. O. S.; CODECEIRA Jr., A. \& ATAIDE, L. - Estudo clínico e liquórico de uma série de casos de polirradiculoneurites. Neurobiologia (Recife) 32:1, 1969.

13. FERNANDEZ MARTIN, F. \& ORTIZ, M. - Diplegia facial en el curso de una infección por herpes simple. Arch. Neurobiol. (Madrid) 32:387, 1969.

14. FORTES-REGO, J. - Etiologia da paralisia facial periférica. Arq. Neuro-Psiquiat. (São Paulo) 32:131, 1974.

15. FORTES-REGO, J. - Diplegia facial traumática. Arq. Neuro-Psiquiat. (São Paulo) 33:389, 1975 .

16. FORTES-REgO, J.; ARIAS, J. P. \& REBOLlo, M. A. - Tumores del tronco cerebral en la infancia. Neurobiologia (Recife) 33:251, 1970.

17. FORTES-REBO, J. \& REBOLLO, M. A. - Sindrome de Melkersson familiar. Neurobiologia (Recife) 34:139, 1971.

18. GARCIA FERNANDEZ, E. - Paralisis facial y sus causas. An. Esp. Odontoestomat. 28:419. 1969 .

19. GROVES, J. - Facial palsies: selection of cases for treatment. Proc. Roy. Soc. Med. 66:545, 1973 .

20. HARIGA, J. - Polynévrites et polyradiculonévrites infectieuses. Rev. Médicale (Liège) 20:186, 1965.

21. HERMANS, P. E.; GOLDSTEIN, N. P. \& WELlMAN, W. E. - Mollaret's meningitis and differential diagnosis of recurrent meningitis. Ame. J. Med. $52: 128,1972$.

22. JAIN, K. K. - Sciatica and herpes simplex. J. Neurosurg. 41:518, 1974.

23. KOBAYASHI, T. - Bilateral facial palsy. Excerpta Medica 31:667, 1974 (Resumo).

24. LAYZER, R. B. \& CONANT, M. A. - Neuralgia in recurrent herpes simplex. Arch. Neurol. $31: 233,1974$.

25. LEIBOWITZ, U. - Epidemic incidence of Bell's palsy. Brain 92:109, 1969.

26. LEVY, J. A. \& SANVITO, W. - Polirradiculoneurites: considerações sôbre 111 casos. Rev. Hosp. Clin. Fac. Med. São Paulo 20:239, 1965.

27. MARSHALL, J. — The Landry-Guillain-Barré syndrome. Brain 86:55, 1963.

28. McCORMIK, D. V. - Herpes simplex virus as cause of Bell's palsy. Lancet 1:937, 1972 .

29. McGoverN, F. H. - Bilateral Bell's palsy. Laryngoscope 75:1070, 1965.

30. MeGoverN, F. H. - Facial paralysis. Arch. Otolaryng. 96:92, 1972.

31. MENDONCA, D. - A case of infectious mononucleosis presenting with bilateral facial palsy. Excerpta Medica 25:694, 1972 (Resumo).

32. Miller, H. - Facial paralysis. Brit. Med. J. 3:815, 1967.

33. MORRIS, H. H. \& PETERS, B. H. - Recurrent sciatica associated with herpes simplex. J. Neurosurg. 41:97, 1974.

34. NAUFAL, P. M. \& SCHUKNECHT, H. F. - Neuropathy in diabetes mellitus. Arch. Otolaryng. 96:468, 1972.

35. PUPO, P. P.; ZUKERMAN, E.; CRUZ, N. A.; LIMA, J, G. C.; JORDY, C. \& BRAGA, F. M. - Formas bulbares da sindrome de Guillain-Barré. Arq. Neuro-Psiquiat. (São Paulo) 17:364, 1959.

36. RONTAL, E. \& SIGEL, M. E. - Bilateral facial paralysis. Laryngoscope 82: 607, 1972.

37. SADE, J. - Pathology of Bell's palsy. Arch. Otolaryng. 95:406, 1972.

38. SAUNDERS, W. H. - Viral infections and cranial nerve paralysis. Arch. Otolaryng. $85: 90,1963$. 
39. SLINVINSCHI, R.; BUZNEANU, R. \& RUSU, F. - Leptospirosis facial diplegia during convalescence in a case of leptospirosis grippotyphosa. Excerpta Medica 25:124, 1972 (Resumo).

40. TOMITA, H.; HAYAKA'WA, W. \& HONDO, R. - varicella-zoster virus in idiopathic facial palsy. Arch. Otolaryng. 95:364, 1972.

41. TOMLINSON, A. H.; CHINN, I. J. \& MacCALlum, F. O. - Immunofluorescence staining for the diagnosis of herpes encephalitis. J. Clin. Path. 27: $495,1974$.

42. VASSAllo, L. \& GALEA-DEBONO, A. - Aetiology of Bell's palsy. Lancet 2: 383, 1972 .

Departamento de Medicina Especializada - Faculdade de Ciências da Sakde - 70000 Brasilia, D.F. - Brasil. 